\title{
Sustained Striatal Ciliary Neurotrophic Factor Expression Negatively Affects Behavior and Gene Expression in Normal and R6/1 Mice
}

\author{
Eileen M. Denovan-Wright, ${ }^{1}$ Marissa Attis, ${ }^{1}$ Edgardo Rodriguez-Lebron, ${ }^{2}$ \\ and Ronald J. Mandel ${ }^{3 \star}$ \\ ${ }^{1}$ Department of Pharmacology, Dalhousie University, Halifax, Nova Scotia, Canada \\ ${ }^{2}$ Department of Neurology, University of Michigan, Ann Arbor, Michigan \\ ${ }^{3}$ Department of Neuroscience, University of Florida McKnight Brain Institute and Powell Gene \\ Therapy Center, University of Florida College of Medicine, Gainesville, Florida
}

Huntington's disease (HD) is a neurodegenerative disorder caused by an elongation of CAG repeats in the $H D$ gene, which encodes a mutant copy of huntingtin with an expanded polyglutatmine repeat. Individuals who are affected by the disease suffer from motor, cognitive, and emotional impairments. Levels of certain striatal-enriched mRNAs decrease in both HD patients and transgenic HD mice prior to the development of motor symptoms and neuronal cell death. Ciliary neurotrophic factor (CNTF) has been shown to protect neurons against chemically induced toxic insults in vitro and in vivo. To test the hypothesis that CNTF might protect neurons from the negative effects of the mutant huntingtin protein in vivo, CNTF was continuously expressed following transduction of the striatum by recombinant adeno-associated viral vectors (rAAV2). Wild-type and R6/1 HD transgenic (R6/1) mice that received bilateral or unilateral intrastriatal injections of rAAV2-CNTF experienced weight loss. The CNTFtreated R6/1 HD transgenic mice experienced motor impairments at an earlier age than expected compared with age-matched control R6/1 HD transgenic animals. CNTF also caused abnormal behavior in WT mice. In addition to behavioral impairments, in situ hybridization showed that, in both WT and R6/1 mice, CNTF expression caused a significant decrease in the levels of striatal-enriched transcripts. Overall, continuous expression of striatal CNTF at the dose mediated by the expression cassette used in this study was detrimental to HD and wild-type mice. ๑) 2008 Wiley-Liss, Inc.

Key words: recombinant adeno-associated virus; NGFI-A; striatal transcripts; cannabinoid receptors; preproenkephalin

Huntington's disease (HD) is an inherited neurodegenerative disorder, characterized by progressive decline in motor and cognitive ability and emotional disturbances (Huntington's Disease Collaborative Research
Group, 1993). HD results from inheritance of one copy of the $H D$ gene with more than 36 CAG repeats within the polymorphic CAG repeat locus in exon 1. CAG triplet repeats are translated into polyglutamine (PolyQ), and the extended polyglutamine tract in mutant huntingtin leads to a conformational change in huntingtin protein resulting in a protein that is toxic to a subpopulation of neurons, especially the medium-sized spiny neurons that reside in the caudate and putamen (Walling et al., 1998). In the early stages of the disease, patients may show symptoms without significant loss of cells, suggesting that neuronal dysfunction precedes cell death (Young et al., 1986; Sharp et al., 1995). In fact, mutant huntingtin expression disrupts the regulation of basal neuronal transcriptional activity in both presymptomatic HD transgenic mice and HD patients (Cha, 2000; Luthi-Carter et al., 2000, 2002; Naver et al., 2003; Sugars and Rubinsztein, 2003; Hebb et al., 2004; Hu et al., 2004; Li and Li, 2004; McCaw et al., 2004; Desplats et al., 2006; Gomez et al., 2006; Hodges et al., 2007; Kuhn et al., 2007), and, even without a thorough understanding of how decreases in specific mRNAs and proteins impact disease progression in $\mathrm{HD}$, monitoring

Supplementary Material for this article is available online at http:// www.mrw.interscience.wiley.com/suppmat/0360-4012/suppmat/ (www. interscience.wiley.com)

Contract grant sponsor: NIH (to R.J.M., E.D.-W.); Contract grant sponsor: Hereditary Disease Foundation (R.J.M.); Contract grant sponsor: Canadian Institutes of Health Research (E.D.-W.); Contract grant sponsor: Huntington Society of Canada through the Laura's Hope Fund (E.D.-W.).

*Correspondence to: Ron Mandel, Department of Neuroscience, University of Florida McKnight Brain Institute and Powell Gene Therapy Center, University of Florida College of Medicine, Gainesville, FL 32610-0244. E-mail: rmandel@ufl.edu

Received 9 September 2007; Revised 27 November 2007; Accepted 29 November 2007

Published online 21 February 2008 in Wiley InterScience (www. interscience.wiley.com). DOI: 10.1002/jnr.21636 
the levels of specific mutant huntingtin-affected mRNAs provides a potential method for quantifying the therapeutic benefits of pharmacological agents.

Ciliary neurotrophic factor (CNTF) is a growth factor that promotes the growth, differentiation, and survival of neurons (Hefti, 1997). The binding of CNTF to its receptor results in changes in intracellular signaling pathways. The receptor for CNTF is a trimer composed of leukemia inhibitory factor receptor $\beta$, glycoprotein 130, and a CNTF-specific $\alpha$ receptor (Neet and Campenot, 2001). CNTF binds specifically to the CNTF-specific $\alpha$ receptor, which in turn leads to the activation of Janus tyrosine kinase. Members of the signal transduction activator of transcription (STAT) family of transcription factors are phosphorylated and activated due to the activation of Jak kinases (Neet and Campenot, 2001). Prior to activation by CNTF, the STAT proteins are located in the cytoplasm. However, after binding of CNTF, the STAT proteins are translocated to the nucleus. This new signaling cascade targets the nucleus, ultimately resulting in changes in gene expression (Segal and Greenberg, 1996; Bonni and Greenberg, 1997).

CNTF and other trophic factors have been considered potential therapeutic treatments for a wide range of nervous system disorders (Emerich and Thanos, 2006). In vitro studies with CNTF demonstrated that it supports the survival of parasympathetic neurons from the chick ciliary ganglia (Adler et al., 1979; Arakawa et al., 1990; Sendtner et al., 1990). Further studies have shown that CNTF also has trophic effects on other populations of central and peripheral neurons (Bachoud-Levi et al., 2000; Vergara and Ramirez, 2004). In 2000, Mittoux et al. implanted baby hamster kidney (BHK) cells that were engineered to secrete CNTF into an excitotoxinlesioned animal model that reproduces the pattern of cell loss observed in $\mathrm{HD}$. They found that delivering low doses of CNTF intracerebrally protected neurons from degeneration and restored neostriatal function in neurotoxin-induced models (Mittoux et al., 2000; Emerich, 2004; Emerich and Winn, 2004). However, several studies have documented that rodents as well as humans receiving systemic delivery of CNTF experience weight loss (Henderson et al., 1994; Miller et al., 1996; Ettinger et al., 2003; Kokoeva et al., 2005).

We chose, based on the previously documented neuroprotective effects of CNTF in vitro and in vivo, to administer CNTF into the striatum of R6/1 HD transgenic mice. We hypothesized that continuous intrastriatal administration of CNTF in this genetic model of HD could potentially preserve the function of striatal neurons, which are particularly susceptible to the toxic effects of mutant huntingtin. To observe the effects of chronic administration of CNTF on cells in the striatum, a recombinant adeno-associated viral vector was engineered to express a secretable form of CNTF and packaged into viral particles (rAAV2-CNTF). rAAV vectors have been selected for use in the CNS because of their inherent safety and neurotropism (Mandel et al., 2006). These replication-deficient viral vectors can efficiently deliver genetic cargo into defined brain regions such as the striatum. AAV2-based viral vectors preferentially transduce striatal neurons (Burger et al., 2004; Taymans et al., 2007) when delivered to the parenchyma of the striatum and provide for continuous production of the transgene throughout the life of the animal (Mandel et al., 2006). Moreover, a single striatal injection of rAAV2 vector does not lead to chronic changes in gene expression profile, striatal pathology, weight loss, or abnormal behavior (Mandel et al., 1998; Kirik et al., 2000; Peden et al., 2004; Rodriguez-Lebron et al., 2005; Denovan-Wright et al., 2007; Herzog et al., 2007). Therefore, this vector system seems ideal to study continuous delivery of trophic factors in mouse models of neurological disorders.

Given that CNTF and other trophic factors have shown neuroprotective effects in cell culture and in excitotoxic lesion models of HD, our goal was to determine whether rAAV2-mediated CNTF could protect striatal neurons from the toxic effect of the $\mathrm{N}$-terminal of mutant huntingtin expressed in a transgenic model of $\mathrm{HD}$, which more closely resembles the human disease than lesion models. It is known that the detrimental effects of mutant huntingtin on neurons throughout the brain precede selective degeneration seen in the caudate and putamen (Smith et al., 2006). We chose to observe the effects of sustained CNTF expression on behavioral phenotype, gene expression, and cell morphology in R6/1 mice, because this strain is slower to progress, has a later onset of motor abnormalities, and has a longer life span than the R6/2 strain (Mangiarini et al., 1996). Importantly, these mice have alterations in gene expression and phenotype but do not show significant neurodegeneration (Naver et al., 2003; Hodges et al., 2007). Overall, we found that CNTF negatively affected the behavior and intrastriatal gene expression of wild-type (WT) and HD transgenic mice.

\section{MATERIALS AND METHODS}

\section{Animals}

Transgenic R6/1 male mice were originally purchased from Jackson Laboratories (Bar Harbor, ME). A colony was maintained by crossing hemizygous R6/1 males from within the colony back with CBA $\times$ C57BL/6 females, and each animal was genotyped as described previously (Gomez et al., 2006). Animal care and handling followed the guidelines of the Canadian Council on Animal Care and were approved by the Carleton Animal Care committee at Dalhousie University. Every effort was made to minimize the number of animals used in this study and to minimize their discomfort.

\section{Expression of rAAV2-Encoded CNTF Gene in R6/1 Mice}

The complete coding region for recombinant human CNTF fused to the human growth hormone signal peptide for secretion (Bok et al., 2002) was PCR amplified using primers containing HindIII/NsiI sites and introduced into the multiple cloning site of the pTR-UF12-IRES-GFP plasmid 
under the regulation of a chicken $\beta$-actin promoter. This strategy resulted in a bicistronic transgene that produced both CNTF and GFP because of the presence of an internal ribosomal entry site (IRES) element between both coding sequences. rAAV2 vector coding for CNTF was produced and purified at the Gene Therapy Center Vector core facility at the University of Florida as described previously in detail (Zolotukhin et al., 2002). Briefly, 293 cells were cotransfected with pDG (a plasmid containing all required adenoviral genes and rep and cap) and pTR-UF12-CNTF (described above). The cells were lysed, and the supernatant was purified using an iodixenol gradient, followed by a hand-packed heparin column. The purified virus was then dialyzed such that the final stock contained only rAAV and phosphate-buffered saline. The vector was titered using a dot blot for vector genomes. The rAAV2-UF12-CNTF virus was $2.7 \times 10^{12}$ vector genomes $/ \mathrm{ml}$. The vector rAAV2-UF11, which expresses only GFP, was used as a control, and this virus was $4.2 \times 10^{11}$ genome copies/ml (Burger et al., 2004).

Mice were anesthetized with isoflurane and rAAV2CNTF $(1 \mu \mathrm{l})$ was stereotaxically injected in the right striatum via a pulled-glass pipette. The intrastriatal injections for the mice were delivered at a rate of $0.5 \mu \mathrm{l} / \mathrm{min}$ into the right striatum at the following coordinates with respect to Bregma and the surface of the brain: anterior posterior (AP) +0.9 $\mathrm{mm}$, lateral (Lat) $-2.0 \mathrm{~mm}$, dorsal ventral (DV) $-3.3 \mathrm{~mm}$. Bilaterally injected mice received $1 \mu \mathrm{l}$ of rAAV2-CNTF into the left and right striatum [(AP) $+0.9 \mathrm{~mm}$, (Lat) $\pm 2.0 \mathrm{~mm}$, and (DV) $-3.3 \mathrm{~mm}$. After the delivery of the rAAV2CNTF, there was a $1 \mathrm{~min}$ delay before the pipette was slowly raised to a new DV coordinate of $-3.0 \mathrm{~mm}$ to allow the vector to diffuse into the tissue. The glass pipette was left in place $(\mathrm{DV}=-3.0 \mathrm{~mm})$ for an additional $2 \mathrm{~min}$ before being slowly withdrawn. All animals received a single intraperitoneal injection of the long-lasting analgesic ketoprofen $(2 \mathrm{mg} / \mathrm{kg})$ prior to regaining consciousness.

Four weeks after surgery, the mice in the unilaterally injected treatment group were deeply anesthetized by intraperitoneal injection of $65 \mathrm{mg} / \mathrm{kg}$ sodium pentobarbital and decapitated, and the brains were removed and frozen at $-70^{\circ} \mathrm{C}$. Coronal sections of the brain $(14 \mu \mathrm{m})$ were cut on a cryostat through the rostral-caudal axis of the striatum and placed on Fisherbrand Superfrost slides. Five sections were placed on each slide such that the sections on each slide represented regions of the striatum separated by $\sim 350 \mu \mathrm{m}$. The sections were used for in situ hybridization analysis of the levels of mRNA. Genbank accession numbers for all of the hybridization probes, with the exception of those used to detect dynamin and GFP mRNA, have been documented by Rodriguez-Lebron et al. (2005). The dynamin oligonucleotide (5'-CACTGGCTTTCTCTTTGTCCCCAACAC GCTC-3') was complementary to nts 1943-1973 of the mouse Mus musculus dynamin 1 cDNA (Genbank accession No. NM_010065), whereas the GFP oligonucleotide (5'GGCGGAGCGGGGCACGGGGCGAAGGCAGCG-3') was complementary to nts 485-514 of the Expression vector pGIpec, partial sequence (Genbank accession No. AF4282). The methods for in situ hybridization, cresyl violet staining, and immunohistochemical analysis using Hum-1 antibody were performed on coronal sections of the mice that received unilateral injections of rAAV2-CNTF, described previously (Rodriguez-Lebron et al., 2005). mRNA levels were analyzed in Kodak 1D Image Analysis software. The optical density of the hybridization signal for each mRNA and each animal was normalized by subtracting the local slide background. The optical density of the corrected hybridization signal was subjected to two-way ANOVA assessing the influence of genotype and treatment of independent groups of mice. A 0.05 level of significance was adopted for all comparisons. ELISA was employed to determine levels of human CNTF in the injected striatum of each mouse following transduction by rAAV2-CNTF. Tissue from 10 sections of the injected and uninjected striata of each unilaterally injected mouse was isolated from the slides and homogenized in PBS containing protease inhibitor (Complete Mini protease inhibitor cocktail tablets; Roche, Indianapolis, IN). The concentration of protein in each sample was determined by BCA (Bio-Rad, Hercules, CA). Levels of CNTF were quantified using the Quantikine human CNTF ELISA Assay (R\&D Systems, Minneapolis, $\mathrm{MN})$. The ratio of CNTF (pg)/total protein (mg) was calculated and subjected to two-way ANOVA.

\section{Behavioral Assessment}

The bilaterally injected mice were observed over a 6week period following injection of rAAV2-CNTF. Behavioral analysis was done on a weekly basis by a technician who was blind to the genotype and treatment group of all animals. The behaviors and phenotype were measured as described by Ditzler et al. (2003; see Suppl. Table I). This scoring system is designed to rate HD-like behaviors in mice and to indicate an individual mouse's level of abnormal behavior. Wild-type mice routinely received a cumulative score of 0 .

\section{Statistical Analysis}

ANOVA was used to evaluate the probability of differences between experimental groups. Where appropriate, oneway ANOVA was performed, and individual post hoc differences were assessed using Tukey's honestly significant multiple comparisons. Student's $t$-tests were used where appropriate. Data are presented as mean \pm SEM. $P<0.05$ was used as the significance threshold throughout the study.

\section{RESULTS}

\section{Effect of rAAV-CNTF Administration on Appearance and Behavior}

rAAV2-CNTF was administered bilaterally into the left and right striata of 10 -week-old WT mice $(\mathrm{n}=7$, WT + CNTF) and 10-week-old R6/1 HD transgenic mice ( $\mathrm{n}=7, \mathrm{R} 6 / 1+\mathrm{CNTF}$ ). The controls included untreated WT $(\mathrm{n}=7$ ) and R6/1 HD transgenic ( $\mathrm{n}=$ 6) littermates. The difference between the mass of each mouse at 10 and 16 weeks of age was calculated. Over the 6-week period, the untreated R6/1 and WT mice gained on average $1.7( \pm 0.6)$ and $3.2( \pm 1.0) \mathrm{g}$, respectively. In contrast, over the same 6 -week period, the rAAV2-CNTF-treated R6/1 and WT mice lost 2.8 


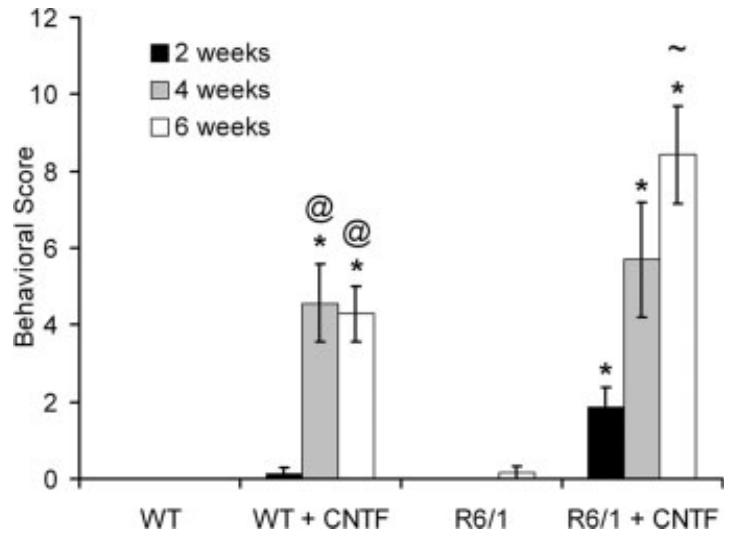

Fig. 1. Bilateral intrastriatal injections of rAAV2-CNTF increased abnormal behaviors in both WT and R6/1 HD transgenic (R6/1) mice. Black, gray, and white bars are the mean behavior ( \pm SEM) at 2,4 , and 6 weeks, respectively. Two-way ANOVA indicated that there was a significant treatment effect. One-way ANOVA and Tukey's post hoc tests were used to compare between groups. ${ }^{\star} P<$ 0.05 vs. untreated wild-type mice at each time point. ${ }^{@} P<0.05$ vs. $\mathrm{WT}+\mathrm{CNTF}$ at 2 weeks within this treatment group. ${ }^{\sim} \mathrm{P}<0.05$ vs. R6/1 + CNTF mice at 2 weeks within this treatment group.

$( \pm 0.7)$ and $1.0( \pm 0.8) \mathrm{g}$, respectively. There was a significant difference in change in body mass in the rAAV2-CNTF-treated WT and R6/1 mice compared with untreated genotype-matched littermates $(P<0.05)$. Intrastriatal administration of rAAV vectors does not alter body weight or behavior in wild-type or R6 transgenic mice (Rodgriquez-Lebron et al., 2005; DenovanWright et al., 2007).

Each mouse was examined for general appearance and behavior (see Suppl. Table I for scoring) on a biweekly basis. The individual scores for each measurement (Suppl. Table II) for each mouse were summed, and the average $( \pm$ SEM) behavior for mice in different treatment groups was calculated at 2, 4, and 6 weeks following the date of surgery. Two-way ANOVA confirmed a significant treatment by genotype effect (Fig. 1). Two weeks after surgery, the scores of the R6/1 + CNTF mice showed significantly more abnormal behavior compared with untreated WT mice $(P<0.05)$. Four and six weeks after surgery, both the WT + CNTF and the R6/1 + CNTF mice displayed significantly more abnormal behavior compared with untreated WT mice $(P<0.05$; Fig. 1). Normally, R6/1 HD transgenic mice start to show abnormal HD-like phenotypes at 16-20 weeks of age (Mangiarini et al., 1996). As expected, therefore, there was no significant difference between untreated WT and untreated R6/1 HD mice at 12, 14, and 16 weeks of age.

The ability of mice to remain on a bar that has increasing speed of revolutions over a defined time period (rotarod) is often used as a measurement of gross motor skills (Carter et al., 1999). Rotarod data were collected 2, 4, and 6 weeks after bilateral injection of rAAV2-CNTF. Two weeks following surgery, there was

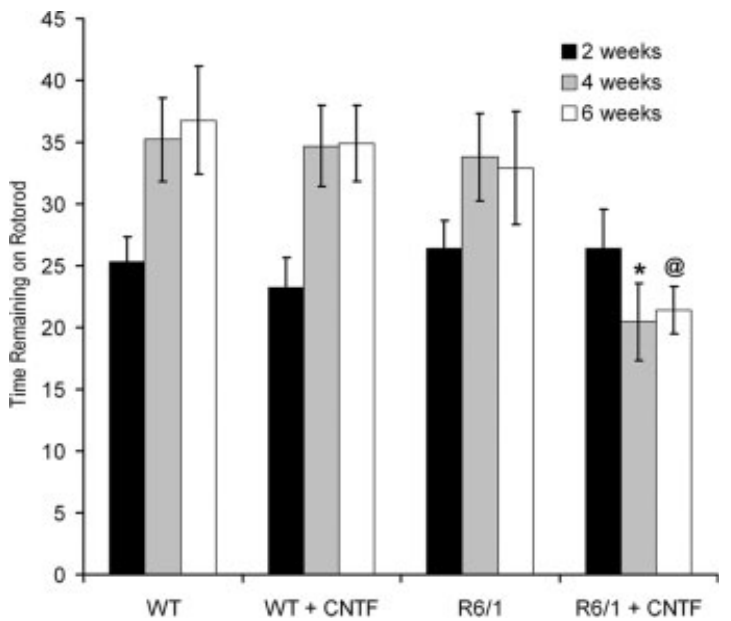

Fig. 2. Bilateral intrastriatal injections of rAAV2-CNTF impaired motor coordination in R6/1 HD transgenic (R6/1) mice 4 and 6 weeks after surgery. Black, gray, and white bars are the mean rotarod score $( \pm \mathrm{SEM})$ at 2,4 , and 6 weeks, respectively. One-way ANOVA was used to compare the mean rotarod score of WT and R6/1 mice that were untreated or received rAAV2-CNTF (WT + CNTF and $\mathrm{R} 6 / 1+\mathrm{CNTF})$ at each time point. ${ }^{\star} P<0.05$ difference from untreated WT 4 weeks after surgery. ${ }^{\circledR} P<0.05$ difference from untreated WT 6 weeks after surgery.

no statistically significant difference among mice in different treatment groups (Fig. 2). However, 4 and 6 weeks after surgery, the rAAV2-CNTF-treated R6/1 mice were unable to remain on the rotating bar as long as untreated WT or R6/1 mice $(P<0.05$; Fig. 2$)$. There was no significant difference in time remaining on the rotating bar among untreated WT mice, rAAV2CNTF-treated WT, and untreated R6/1 mice.

\section{Effects of CNTF on Gene Expression}

In a separate experiment, rAAV2-CNTF was administered unilaterally into the right striata of 15 mice (WT, $\mathrm{n}=6 ; \mathrm{R} 6 / 1, \mathrm{n}=9$ ), and the animals were allowed to survive for 4 weeks. As was observed in the animals that received bilateral injection of rAAV2CNTF, the WT and R6/1 mice that received a unilateral injection of rAAV2-CNTF lost weight $(P<0.05)$. The unilateral injection of rAAV2-CNTF allowed for comparison of mRNA levels in the injected and uninjected striata of each animal. Coronal brain sections were subjected to in situ hybridization to measure the effects of the rAAV2-CNTF vector on levels of specific brain transcripts.

The transcript produced by our rAAV2-CNTF vector contained the open-reading frames for both CNTF and green fluorescence protein (GFP) in order to facilitate the identification of positively transduced cells. Using probes targeting the GFP coding sequence, we observed localized expression of our AAV2-CNTF transcript via in situ hybridization in striatal cells that were confined to the area in proximity to the site of delivery 


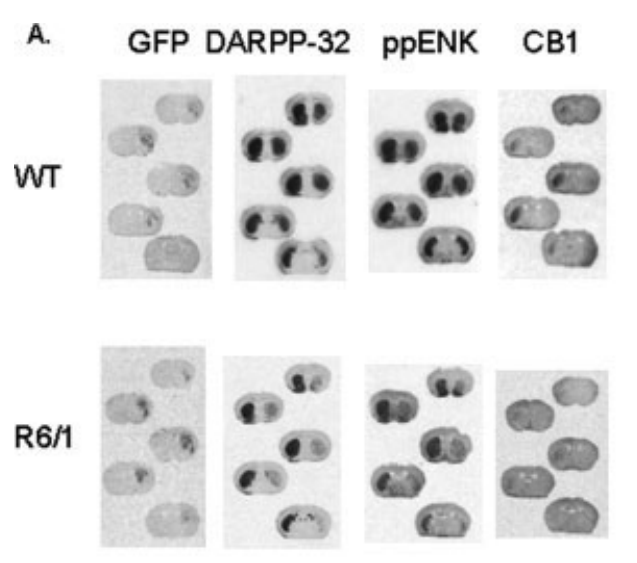

B.

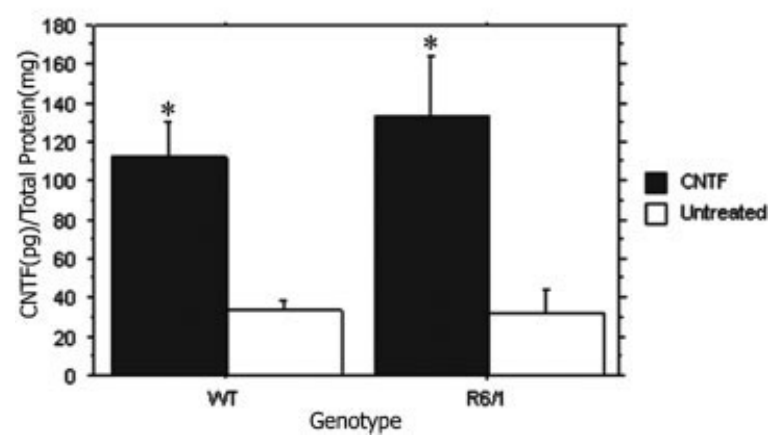

Fig. 3. Injection of rAAV2-CNTF into the striatum leads to expression of green fluorescent protein (GFP) mRNA encoded by the viral vector in a small number of striatal neurons. The levels of DARPP32, ppENK, and CB1 mRNA in the striatum were affected by administration of rAAV2-CNTF throughout the treated striatum in WT and R6/1 transgenic HD mice (R6/1; A). Five coronal sections from one representative mouse that was unilaterally injected with CNTF were subjected to in situ hybridization using mRNA-specific probes as indicated above each set of sections. The coronal sections on each slide are separated by $350 \mu \mathrm{m}$. Transduction of striatal neurons by rAAV2-CNTF increased levels of human CNTF as detected by ELISA (B). The level of CNTF (pg) was normalized to the concentration of total protein in the sample $(\mathrm{mg})$. Error bars indicate 1 SD. ${ }^{\star} P<0.05$ difference between CNTF and untreated striata.

(Fig. 3A). The hybridization signal indicated that a subset of cells within each injected striatum had been transduced and was expressing mRNA encoded by the rAAV2-CNTF vector. Levels of CNTF were quantified by ELISA. The protein levels that reacted with antihuman CNTF in ELISA were significantly higher in the rAAV2-CNTF transduced striatum than the uninjected striatum of both wild-type and R6/1 mice, but there was no difference in CNTF levels in the transduced striatum of wild-type and R6/1 mice (Fig. 3B). The regional distribution of our rAAV2-CNTF transgene as determined by in situ hybridization of mRNA encoded by rAAV2-CNTF vector was compared with the pattern of expression of other mRNAs that are expressed in the striatum and cortex. It appeared that, regardless of genotype, the expressions of DARPP-32, ppENK, CB1, PDE1B, PDE10A, NGFI-A, dynamin, and $\beta$-actin were lower in the hemisphere that received rAAV2-CNTF. Moreover, the decrease in levels of these mRNAs was not confined to regions that expressed rAAV2-CNTF mRNA, but rather the decrease appeared to be in cells throughout a wider region of the injected hemisphere. Adjacent sections that span the rostral-caudal axis of the striatum from one representative WT and one R6/1 mouse that were subjected to unilateral injection of rAAV2-CNTF and in situ hybridization analysis for GFP, DARPP-32, ppENK, and CB1 mRNA levels are shown in Figure 3. To control for the effects of administration of rAAV2 on gene expression, rAAV2-UF11, which expressed GFP but not any other protein, was administered unilaterally to four R6/1 mice. There was no effect on the expression of DARPP-32, ppENK, CB1, PDE1B, PDE10A, NGFI-A, and $\beta$-actin in the mice injected with rAAV2-UF11 compared with uninjected, age- and genotype-matched mice (Suppl. Fig. 1). These data demonstrated that the effects on transcription observed in rAAV2-CNTF-injected animals were caused by expression of CNTF and not delivery of the viral vector or expression of GFP.

ppENK and D2 receptor mRNA are expressed by a subpopulation of medium spiny projection neurons, and levels of these mRNAs are lower in the striatum of several transgenic mouse models of HD (Kuhn et al., 2007). As expected, levels of both these transcripts were higher in the striatum of uninjected WT mice compared with the uninjected R6/1 HD transgenic mice (Fig. 4). Surprisingly, ppENK and D2 mRNA levels were even lower in the rAAV2-CNTF-treated hemisphere of the brain compared with the corresponding region in the untreated side of both WT and R6/1 mice (Fig. 4). CNTF had a greater proportional effect on ppENK and D2 mRNA levels in the rAAV2-CNTF-treated R6/1 compared with the treated WT mice.

DARPP-32, PDE1B, and PDE10A are highly expressed in all medium spiny projection neurons of the striatum, with lower levels of expression in the cortex and olfactory tubercle and expression of mutant huntingtin lowers levels of these mRNAs (Hebb et al., 2004). These transcripts were lower in the uninjected striatum of 16-week-old R6/1 compared with WT mice and lower in the rAAV2-CNTF-treated hemisphere of each animal (Fig. 4). As was observed with ppENK and D2 mRNA, it appeared that CNTF affected mRNA levels of DARPP-32, PDE1B, and PDE10A in cells that were distributed throughout the striatum and not just those cells that were directly transduced by the viral vector (Fig. 3). The proportional decline of DARPP-32 resulting from CNTF was greater in the R6/1 mice compared with their WT counterparts. However, the proportional declines of PDE1B and PDE10A are not significantly different in the CNTF-treated WT mice compared with the CNTF-treated R6/1 HD transgenic mice. 

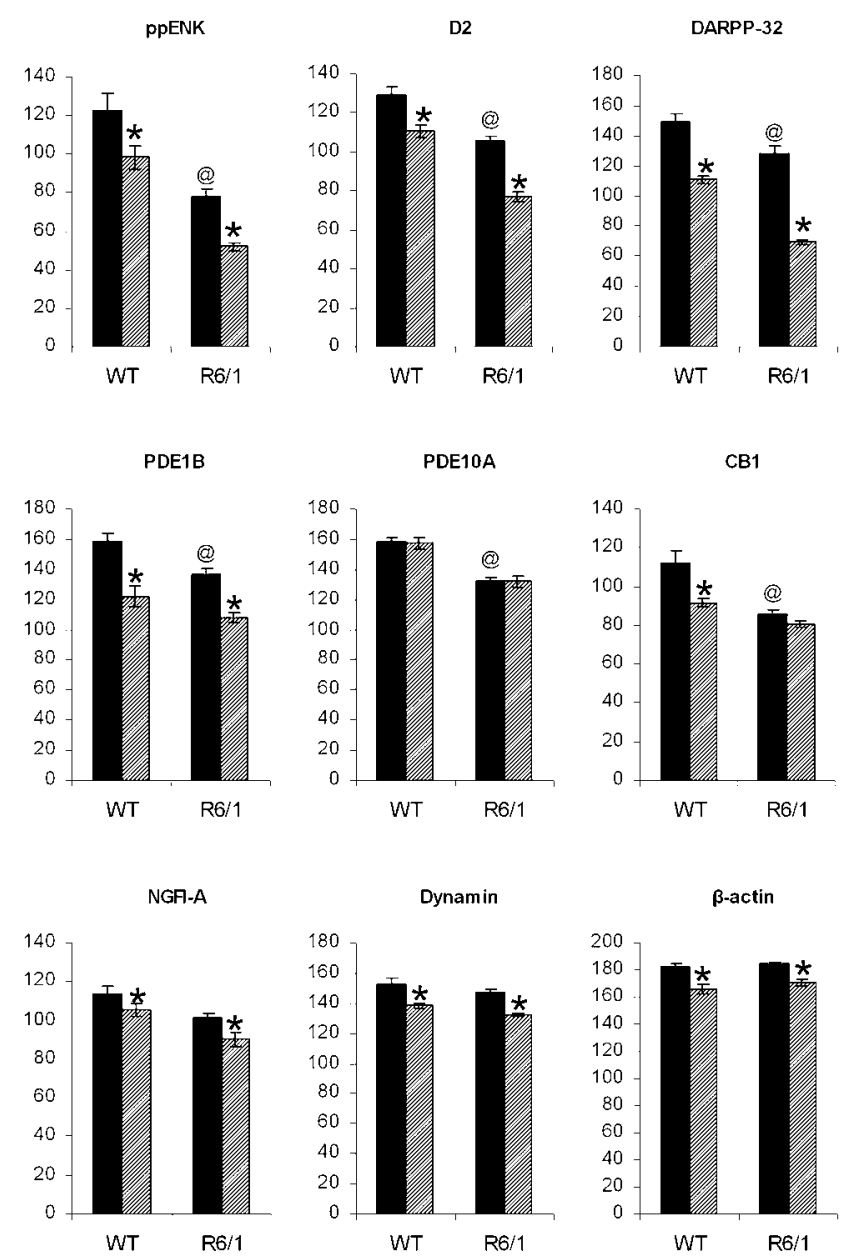

Fig. 4. Administration of CNTF over 4 weeks decreased levels of mRNA. rAAV2-CNTF was injected into the right striatum, and the average optical density ( \pm SEM) of the hybridization signal in the untreated (solid bars) WT (WT) and R6/1 transgenic HD (R6/1) and CNTF-treated (striped bars) WT (WT + CNTF) and R6/1 (R6/1 + CNTF; striped bars) striata were calculated for each probe. $\star P<0.05$ difference between CNTF-treated and untreated striata of the same genotype. ${ }^{@} P<0.05$ difference between untreated striata of WT and R6/1 mice.

CB1 mRNA is expressed in neurons throughout the brain, with highest levels of expression in neurons in the lateral striatum (McCaw et al., 2004). Levels of CB1 were found to be higher in uninjected WT compared with uninjected R6/1 mice (Fig. 4). Levels of CB1 mRNA in the lateral striatum were affected by rAAV2CNTF expression in the striatum of WT mice (Fig. 3). Levels of CB1 mRNA in the lateral striatum of R6/1 HD transgenic mice decline in young R6/1 mice to levels that are uniform throughout the brain (McCaw et al., 2004) such that further rAAV2-CNTF-dependent reductions in mRNA levels in the neurons of the lateral striatum might not have been measurable. There was no significant difference in the proportional decrease of $\mathrm{CB} 1$ in WT and R6/1 HD transgenic mice.
NGFI-A is expressed at low levels in the cortex as well as the striatum (Luthi-Carter et al., 2000). Levels of NGFI-A mRNA were higher in uninjected WT compared with uninjected R6/1 HD transgenic mice (Fig. 4). NGFI-A mRNA levels decreased in the rAAV2CNTF-injected striatum of R6/1 HD transgenic mice. Although NGFI-A is known to decrease in transgenic HD mice, it can be induced in response to cell stress and acts as an indicator of inflammatory response or increased neuronal response to stimuli (MacGibbon et al., 2002). We did not observe an increase in NGFIA mRNA in the cells transduced by rAAV2-CNTF or in cells adjacent to transduced cells, demonstrating that CNTF did not induce expression of NGFI-A.

Dynamin is expressed in the motor cortex and the piriform cortex and is known to decrease in $\mathrm{HD}$ YAC72 mice (Zuccato et al., 2003). We observed a decline in the levels of dynamin mRNA in the cortex of rAAV2-CNTF- treated WT and R6/1 HD transgenic mice (Fig. 4). Similarly, a decrease in the levels of $\beta$ actin mRNA was observed in the rAAV2-CNTF-treated striatum of both the WT and R6/1 HD transgenic mice (Fig. 4). There was no significant difference in the proportional decrease of dynamin or $\beta$-actin mRNA in rAAV2-CNTF treated WT and R6/1 HD transgenic mice. It appeared that the effect of CNTF was not limited to the striatum that was injected with the viral vector but was able to affect distal neurons in the cortex that were ipsilateral to the injected striatum.

\section{Cell Morphology}

To determine whether the CNTF-dependent down-regulation of mRNA levels was due to a loss of cells, tissue from WT and R6/1 mice that had received unilateral intrastriatal injections of rAAV2-CNTF were stained with cresyl violet (Fig. 5). No obvious differences were noted in the size, morphology, or distribution of cresyl violet-stained neuronal cell bodies between the untreated left and rAAV2-CNTF-treated right striata in WT or R6/1 mice, demonstrating that the neurons were present following CNTF treatment. An antibody (Hum 1) that specifically recognizes the amino-terminus of human mutant huntingtin in NII protein aggregrates and that cross-reacts with cytoplasmic proteins in striatal neurons of WT and R6/1 mice (Rodriguez-Lebron et al., 2005) was also used to determine the relative distribution of neurons and NIIs following transduction by rAAV2-CNTF. As was observed using cresyl violet staining, no difference in the size or distribution of Hum 1-immunoreactive proteins dispersed within neurons or aggregated in NIIs was observed in animals receiving rAAV2-CNTF (data not shown).

\section{DISCUSSION}

In this study, we assessed the effects of continuous intrastriatal CNTF expression on the behavior, weight, and gene expression profile of WT and R6/1 HD transgenic mice following transduction of striatal neurons 


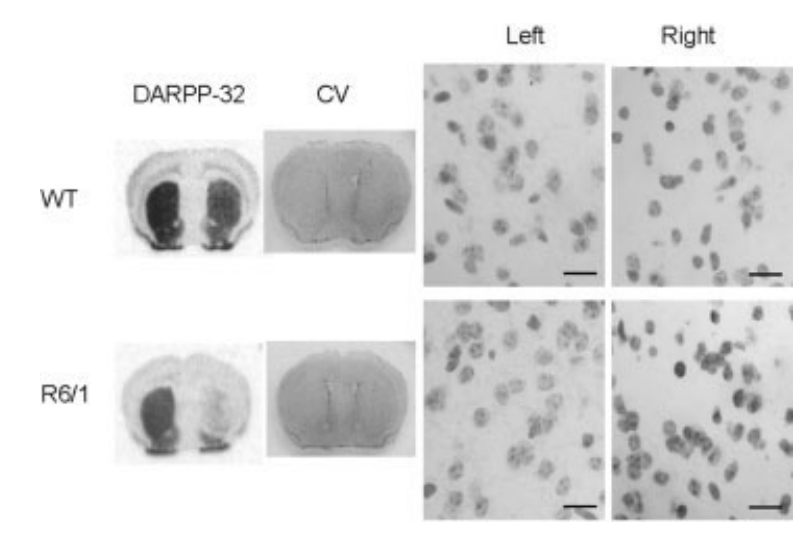

Fig. 5. CNTF did not affect cell number or morphology. Adjacent coronal sections from WT (WT) and R6/1 HD transgenic (R6/1) mice that received rAAV2-CNTF in the right striatum were subjected to in situ hybridization with a DARPP-32-specific probe or stained with cresyl violet $(\mathrm{CV})$. The genotypes of the representative sections are indicated on the left. The animals were 16 weeks of age. Photomicrographs of the cresyl violet-stained section from the left and right striatum are shown. Scale bars $=20 \mu \mathrm{m}$.

with a single injection of rAAV2-CNTF. We hypothesized that intrastriatal delivery of rAAV2-CNTF would delay the onset of motor abnormalities in R6/1 HD transgenic mice and slow or prevent mutant huntingtininduced decreases in a subset of striatal-enriched mRNAs. Originally, we planned to observe the mice for 10 weeks following bilateral injections of rAAV2CNTF. However, 6 weeks following surgery, these mice were sacrificed after displaying obvious adverse effects that were associated with striatal CNTF overexpression.

Biweekly weight measurements indicated that the R6/1 HD transgenic and WT mice that received intrastriatal CNTF experienced weight loss, whereas untreated WT and R6/1 mice gained weight over the same time period. Weight loss was specific to CNTF overexpression, in that injecting rAAV2 expressing GFP alone or active ribozymes into the brain of $\mathrm{R} 6 / 1$ mice does not result in weight loss (Mandel et al., 1998; Kirik et al., 2000; Peden et al., 2004; Rodriguez-Lebron et al., 2005; Herzog et al., 2007). CNTF is well known to induce weight loss through hypothalamic pathways even in leptin-resistant mice (Lambert et al., 2001), and systemic delivery in obese humans leads to significant weight loss (Ettinger et al., 2003). Furthermore, CNTF can cause proliferation of hypothalamic neurons, and this may directly change regulation of energy metabolism and cause weight loss in mice (Kokoeva et al., 2005). Moreover, in similar gene transfer studies, lentiviralmediated delivery of CNTF in the striatum of a rat QA model of HD led to a reduction in weight gained compared with LacZ-expressing controls (de Almeida et al., 2001). In contrast to these results, CNTF-dependent effects on weight were not reported when implants of encapsulated $\mathrm{BHK}$ cells or osmotic minipumps were used to deliver CNTF to the brain in other chemically induced models of HD. In more recent studies, however, systemic or intrathecal delivery of CNTF also caused weight loss, as well as cachexia, in rodents (Vergara and Ramirez, 2004). It is likely that differences in administration route, concentration levels, and diffusion of the delivered CNTF account for its apparent variable effects on body mass. R6/1 HD transgenic mice do not gain weight at the same rate as WT littermates (Rodriguez-Lebron et al., 2005), and HD patients lose weight as HD progresses. In fact, HD patients require a substantial increase in caloric intake in order to maintain a constant weight (Trejo et al., 2004). CNTF-induced weight loss, therefore, would be predicted to be additive to the HD-induced weight loss and, thus, could be particularly detrimental to HD patients.

Currently, it is hypothesized that mutant huntingtin abnormally interacts with transcriptional machinery, resulting in transcriptional dysregulation of specific genes (Sugars and Rubinsztein, 2003). It is not known whether changes in specific mRNAs are related to symptoms of HD; however, changes in levels of selected mRNAs can be followed as markers of HD progression. We predicted that, if CNTF were acting as a neuroprotective agent to counter the toxic effects of mutant huntingtin, we might see a slowing of the loss of these mRNAs, which might have correlated with a delay in the onset of abnormal motor phenotype. In situ analysis revealed that mRNA levels of DARPP-32, ppENK, D2, PDE10A, PDE1B, NGF1-A, $\beta$-actin, and dynamin decreased significantly throughout the brain hemisphere that received rAAV2CNTF in both WT and R6/1 HD transgenic mice. These transcriptional changes are not observed when rAAV2 expressing only GFP is injected into the brain of R6/1 HD transgenics or their WT littermates. Additionally, we found a proportional decline in the levels of PDE1B, PDE10A, NGFI-A, CB1, dynamin, and $\beta$-actin in WT and R6/1 HD transgenic mice injected with rAAV2-CNTF. In contrast, the levels of DARPP-32, ppENK, and D2 decreased to a greater extent in treated R6/1 HD transgenic compared with treated WT mice. This suggests that rAAV2-CNTF equally affected the transcriptional regulation of some genes independent of mutant huntingtin expression, whereas the expression levels of a different set of striatal genes was more sensitive to the effects of CNTF in R6/1 than their WT littermate controls. This mutant huntingtin-dependent differential effect of CNTF on neuronal gene regulation has not been previously reported. Our thorough in situ analysis should help us begin to elucidate the underlying signaling pathways responsible for mediating these effects.

Although we observed focal expression of rAAV2CNTF mRNA, reduced levels of striatal-enriched gene expression extended to striatal cells that were at a distance from directly transduced neurons. This observation suggested that CNTF was secreted from rAAV2-CNTF transduced cells and also affected gene expression in a paracrine fashion. Alternatively, local CNTF-induced 
toxic effects might have led to changes in the gene expression profiles of neighboring or surrounding neurons. Importantly, we did not observe a decrease in the number of striatal neurons, a change in the cell morphology of neurons in the striatum or cortex, or a change in the number or size of NIIs following CNTF administration. Neurons were still capable of gene expression, insofar as mRNAs were detected in the hemisphere that received rAAV2-CNTF even though levels were lower than in the untreated control hemisphere for each animal. It appeared that striatal neurons, although present, were malfunctioning. Taken together, these data indicate that sustained expression of CNTF altered normal gene expression in the striatum of WT and R6/1 transgenic mice. In fact, for each mRNA tested, CNTF had a negative impact on gene expression regardless of the expression of mutant huntingtin. How CNTF expression mediates changes in neuronal gene expression and how these changes might ultimately affect the function of striatal neurons in the HD brain is not clear at this point.

At the phenotypic level, development and progression of abnormal behaviors started to occur at 12 weeks of age, or 2 weeks postsurgery, in the rAAV2-CNTFtreated R6/1 HD transgenic mice, as opposed to the typically observed age of onset, which is between 16 and 20 weeks in this strain of mice (Mangiarini et al., 1996). The WT mice also experienced abnormal behaviors such as clasping and piloerection commencing at 14 weeks of age, 4 weeks after they had been injected with rAAV2CNTF. Abnormal behaviors have not been observed previously in WT mice of this strain. The performance of the rAAV2-CNTF-treated R6/1 HD transgenic mice on the rotarod was impeded, in that the mice were unable to remain on the rotating bar as long as agematched treated WT, untreated WT, or untreated R6/1 mice. Contrary to our initial hypothesis, it appeared that continuous striatal overexpression of CNTF at the levels mediated by rAAV2 transduction exacerbated the development of abnormal motor behaviors in R6/1 HD transgenic mice. Moreover, the development of abnormal phenotype in the treated WT mice suggests CNTFmediated toxic effects that are independent of mutant huntingtin expression. Similar toxic effects were observed following the delivery of a lentivirus overexpressing CNTF in a mouse with a yeast artificial chromosome expressing an expanded (Q72), full-length human huntingin gene (Zala et al., 2004). Striatal CNTF overexpression induced both abnormal patterns of striatal transcription and behavioral abnormalities, suggesting that striatal transcripts are a reasonable indicator of basal ganglia dysfunction in mice but not necessarily a causal etiological factor (Denovan-Wright et al., 2007). However, the precise mechanisms of CNTF overexpression-induced molecular and/or behavioral abnormalities are not clear, and the data presented here do not elucidate any mechanism.

The use of CNTF for the treatment of HD, and other neurodegenerative diseases, is considered to have therapeutic potential. In a phase I clinical trial (Bloch et al., 2004), six HD patients received an intraventricular implant of a capsule that contained cells from a BHK cell line that had been engineered to express and release CNTF. Levels of CNTF being released from the capsule prior to implantation ranged from 47 to $619 \mathrm{ng} / \mathrm{ml}$. Immediately after removal, only 11 of 24 capsules secreted detectable levels $(>10 \mathrm{ng} / \mathrm{ml})$ of $\mathrm{CNTF}$, and the 13 other capsules secreted between 15 and $98 \mathrm{ng} / \mathrm{ml}$ CNTF. Levels of secreted CNTF were consistently lower after the capsules had been in patients for 6 months compared with the initial measurements obtained (Bloch et al., 2004). None of the patients treated in this study experienced weight loss, as had been previously documented in other studies (Miller et al., 1996; Ettinger et al., 2003; Vergara and Ramirez, 2004; Kokoeva et al., 2005), nor did they experience any other adverse effects. However, comparison of preoperative and postoperative motor, neuropsychological, and neurological assessments indicated that there was no statistically significant benefit of the intrathecal release of CNTF, suggesting that the levels of CNTF remained below those required for therapeutic benefit. The length of time for which CNTF was secreted and the steadystate brain levels of CNTF after implantation of BHK cells are unknown. The basis of the remarkable lack of adverse effects observed in this capsule-implantation trial are not clear, although it is possible that the sustained steady-state levels of CNTF achieved following implantation of BHK cells were significantly lower compared with those obtained after systemic administration or after the use of virally mediated (rAAV or lentivirus) intracerebral delivery.

Our data suggest that, despite the reported neuroprotective effects of CNTF in chemically induced models of striatal lesions, expression of CNTF in genetic models of HD does not prevent mutant huntingtininduced transcriptional or behavioral abnormalities. More importantly, continuous CNTF expression in the striatum of R6/1 mice exacerbated mutant huntingtin toxicity and induced mutant huntingtin-like toxicities in otherwise healthy mice. Different signaling pathways may regulate a differential CNTF response to toxic insults that are induced by chemical or genetic approaches, and this may underlie dissimilarities observed between the two models. Despite the negative effects of CNTF observed in this study, this does not rule out the use of rAAV vectors that produce lower levels of CNTF in a regulated and/or an intermittent fashion to obtain the therapeutic benefits obtained using other delivery methods in HD models. The development of such regulated rAAV-CNTF vectors could result in lower adverse effects and ultimately offer some therapeutic benefit in the HD clinic.

\section{ACKNOWLEDGMENT}

We thank M. Huang for excellent technical assistance. 


\section{REFERENCES}

Adler R, Landa KB, Manthorpe M, Varon S. 1979. Cholinergic neuronotrophic factors: intraocular distribution of trophic activity for ciliary neurons. Science 204:1434-1436.

Arakawa Y, Sendtner M, Thoenen H. 1990. Survival effect of ciliary neurotrophic factor (CNTF) on chick embryonic motoneurons in culture: comparison with other neurotrophic factors and cytokines. J Neurosci 10:3507-3515.

Bachoud-Levi AC, Deglon N, Nguyen JP, Bloch J, Bourdet C, Winkel L, Remy P, Goddard M, Lefaucheur JP, Brugieres P, Baudic S, Cesaro P, Peschanski M, Aebischer P. 2000. Neuroprotective gene therapy for Huntington's disease using a polymer encapsulated BHK cell line engineered to secrete human CNTF. Hum Gene Ther 11:1723-1729.

Bloch J, Bachoud-Levi AC, Deglon N, Lefaucheur JP, Winkel L, Palfi S, Nguyen JP, Bourdet C, Gaura V, Remy P, Brugieres P, Boisse MF, Baudic S, Cesaro P, Hantraye P, Aebischer P, Peschanski M. 2004. Neuroprotective gene therapy for Huntington's disease, using polymerencapsulated cells engineered to secrete human ciliary neurotrophic factor: results of a phase I study. Hum Gene Ther 15:968-975.

Bok D, Yasumura D, Matthes MT, Ruiz A, Duncan JL, Chappelow AV, Zolutukhin S, Hauswirth W, LaVail MM. 2002. Effects of adeno-associated virus-vectored ciliary neurotrophic factor on retinal structure and function in mice with a P216L rds/peripherin mutation. Exp Eye Res 74:719-735.

Bonni A, Greenberg ME. 1997. Neurotrophin regulation of gene expression. Can J Neurol Sci 24:272-283.

Burger C, Gorbatyuk OS, Velardo MJ, Peden CS, Williams P, Zolotukhin S, Reier PJ, Mandel RJ, Muzyczka N. 2004. Recombinant AAV viral vectors pseudotyped with viral capsids from serotypes 1,2 , and 5 display differential efficiency and cell tropism after delivery to different regions of the central nervous system. Mol Ther 10:302-317.

Carter RJ, Lione LA, Humby T, Mangiarini L, Mahal A, Bates GP, Dunnett SB, Morton AJ. 1999. Characterization of progressive motor deficits in mice transgenic for the human Huntington's disease mutation. J Neurosci 19:3248-3257.

Cha JHJ. 2000. Transcriptional dysregulation in Huntington's disease. Trends Neurosci 23:387-392.

de Almeida LP, Zala D, Aebischer P, Deglon N. 2001. Neuroprotective effect of a CNTF-expressing lentiviral vector in the quinolinic acid rat model of Huntington's disease. Neurobiol Dis 8:433-446.

Denovan-Wright EM, Rodriguez-Lebron E, Lewin AS, Mandel RJ. 2007. Unexpected off-targeting effects of anti-huntingtin ribozymes and siRNA in vivo. Neurobiol Dis. (Epub ahead of print).

Desplats PA, Kass KE, Gilmartin T, Stanwood GD, Woodward EL, Head SR, Sutcliffe JG, Thomas EA. 2006. Selective deficits in the expression of striatal-enriched mRNAs in Huntington's disease. J Neurochem 96:743-757.

Ditzler S, Stoeck J, LeBlanc M, Kooperberg C, Hansen S, Coppin L, Olson JM. 2003. A rapid neurobehavioral assessment reveals that FK506 delays symptom onset in R6/2 Huntington's disease mice. Preclinica 1:115-126.

Emerich DF. 2004. Dose-dependent neurochemical and functional protection afforded by encapsulated CNTF-producing cells. Cell Transplant 13:839-844.

Emerich DF, Thanos CG. 2006. Intracompartmental delivery of CNTF as therapy for Huntington's disease and retinitis pigmentosa. Curr Gene Ther 6:147-159.

Emerich DF, Winn SR. 2004. Neuroprotective effects of encapsulated CNTF-producing cells in a rodent model of Huntington's disease are dependent on the proximity of the implant to the lesioned striatum. Cell Transplant 13:253-259.

Ettinger MP, Littlejohn TW, Schwartz SL, Weiss SR, McIlwain HH, Heymsfield SB, Bray GA, Roberts WG, Heyman ER, Stambler N, Heshka S, Vicary C, Guler HP. 2003. Recombinant variant of ciliary neurotrophic factor for weight loss in obese adults: a randomized, doseranging study. JAMA 289:1826-1832.

Gomez GT, Hu H, McCaw EA, Denovan-Wright EM. 2006. Brainspecific factors in combination with mutant huntingtin induce genespecific transcriptional dysregulation. Mol Cell Neurosci 31:661675.

Hebb ALO, Robertson HA, Denovan-Wright EM. 2004. Striatal phosphodiesterase mRNA and protein levels are reduced in Huntington's disease transgenic mice prior to the onset of motor symptoms. Neuroscience 123:967-981.

Hefti F. 1997. Neurotrophic factor therapy—keeping score. Nature Med 3:497-498.

Henderson JT, Seniuk NA, Richardson PM, Gauldie J, Roder JC. 1994. Systemic administration of ciliary neurotrophic factor induces cachexia in rodents. J Clin Invest 93:2632-2638.

Herzog CD, Dass B, Holden JE, Stansell J 3rd, Gasmi M, Tuszynski MH, Bartus RT, Kordower JH. 2007. Striatal delivery of CERE-120, an AAV2 vector encoding human neurturin, enhances activity of the dopaminergic nigrostriatal system in aged monkeys. Mov Disord 22: $1124-1132$.

Hodges A, Hughes G, Brooks S, Elliston L, Holmans P, Dunnett SB, Jones L. 2007. Brain gene expression correlates with changes in behavior in the R6/1 mouse model of Huntington's disease. Genes Brain Behav (in press).

Hu H, McCaw EA, Hebb AL, Gomez GT, Denovan-Wright EM. 2004. Mutant huntingtin affects the rate of transcription of striatum-specific isoforms of phosphodiesterase 10A. Eur J Neurosci 20:3351-3363.

Huntington's Disease Collaborative Research Group. 1993. A novel gene containing a trinucleotide repeat that is expanded and unstable on Huntington's disease chromosomes. Cell 72:971-983.

Kirik D, Rosenblad C, Bjorklund A, Mandel RJ. 2000. Long-term rAAV-mediated gene transfer of GDNF in the rat Parkinson's model: intrastriatal but not intranigral transduction promotes functional regeneration in the lesioned nigrostriatal system. J Neurosci 20:4686-4700.

Kokoeva MV, Yin H, Flier JS. 2005. Neurogenesis in the hypothalamus of adult mice: potential role in energy balance. Science 310:679683.

Kuhn A, Goldstein DR, Hodges A, Strand AD, Sengstag T, Kooperberg C, Becanovic K, Pouladi MA, Sathasivam K, Cha JH, Hannan AJ, Hayden MR, Leavitt BR, Dunnett SB, Ferrante RJ, Albin R, Shelbourne P, Delorenzi M, Augood SJ, Faull RL, Olson JM, Bates GP, Jones L, Luthi-Carter R. 2007. Mutant huntingtin's effects on striatal gene expression in mice recapitulate changes observed in human Huntington's disease brain and do not differ with mutant huntingtin length or wild-type huntingtin dosage. Hum Mol Genet 16:1845-1861.

Lambert PD, Anderson KD, Sleeman MW, Wong V, Tan J, Hijarunguru A, Corcoran TL, Murray JD, Thabet KE, Yancopoulos GD, Wiegand SJ. 2001. Ciliary neurotrophic factor activates leptin-like pathways and reduces body fat, without cachexia or rebound weight gain, even in leptin-resistant obesity. Proc Natl Acad Sci U S A 98:4652-4657.

Li SH, Li XJ. 2004. Huntingtin-protein interactions and the pathogenesis of Huntington's disease. Trends Genet 20:146-154.

Luthi-Carter R, Strand A, Peters NL, Solano SM, Hollingsworth ZR, Menon AS, Frey AS, Spektor BS, Penney EB, Schilling G, Ross CA, Borchelt DR, Tapscott SJ, Young AB, Cha JHJ, Olson JM. 2000. Decreased expression of striatal signaling genes in a mouse model of Huntington's disease. Hum Mol Genet 9:1259-1271.

Luthi-Carter R, Hanson SA, Strand AD, Bergstrom DA, Chun W, Peters NL, Woods AM, Chan EY, Kooperberg C, Krainc D, Young $\mathrm{AB}$, Tapscott SJ, Olson JM. 2002. Dysregulation of gene expression in the R6/2 model of polyglutamine disease: parallel changes in muscle and brain. Hum Mol Genet 11:1911-1926. 
MacGibbon GA, Hamilton LC, Crocker SF, Costain WJ, Murphy KM, Robertson HA, Denovan-Wright EM. 2002. Immediate-early gene response to methamphetamine, haloperidol, and quinolinic acid is not impaired in Huntington's disease transgenic mice. J Neurosc Res 67:372-378.

Mandel RJ, Rendahl KG, Spratt SK, Snyder RO, Cohen LK, Leff SE. 1998. Characterization of intrastriatal recombinant adeno-associated virus-mediated gene transfer of human tyrosine hydroxylase and human GTP-cyclohydrolase I in a rat model of Parkinson's disease. J Neurosci 18:4271-4284.

Mandel RJ, Manfredsson FP, Foust KD, Rising A, Reimsnider S, Nash K, Burger C. 2006. Recombinant adeno-associated viral vectors as therapeutic agents to treat neurological disorders. Mol Ther 13:463-483.

Mangiarini L, Sathasivam K, Seller M, Cozens B, Harper A, Hetherington C, Lawton M, Trottier Y, Lehrach H, Davies SW, Bates GP. 1996. Exon 1 of the HD gene with an expanded CAG repeat is sufficient to cause a progressive neurological phenotype in transgenic mice. Cell 87:493-506.

McCaw EA, Hu H, Gomez GT, Hebb AL, Kelly ME, Denovan-Wright EM. 2004. Structure, expression and regulation of the cannabinoid receptor gene (CB1) in Huntington's disease transgenic mice. Eur J Biochem 271:4909-4920.

Miller RG, Bryan WW, Dietz MA, Munsat TL, Petajan JH, Smith SA, Goodpasture JC. 1996. Toxicity and tolerability of recombinant human ciliary neurotrophic factor in patients with amyotrophic lateral sclerosis. Neurology 47:1329-1331.

Mittoux V, Joseph JM, Conde F, Palfi S, Dautry C, Poyot T, Bloch J, Deglon N, Ouary S, Nimchinsky EA, Brouillet E, Hof PR, Peschanski M, Aebischer P, Hantraye P. 2000. Restoration of cognitive and motor functions by ciliary neurotrophic factor in a primate model of Huntington's disease. Hum Gene Ther 11:1177-1187.

Naver B, Stub C, Moller M, Fenger K, Hansen AK, Hasholt L, Sorensen SA. 2003. Molecular and behavioral analysis of the R6/1 Huntington's disease transgenic mouse. Neuroscience 122:1049-1057.

Neet KE, Campenot RB. 2001. Receptor binding, internalization, and retrograde transport of neurotrophic factors. Cell Mol Life Sci 58:10211035.

Peden CS, Burger C, Muzyczka N, Mandel RJ. 2004. Circulating antiwild-type adeno-associated virus type 2 (AAV2) antibodies inhibit recombinant AAV2 (rAAV2)-mediated, but not rAAV5-mediated, gene transfer in the brain. J Virol 78:6344-6359.

Rodriguez-Lebron E, Denovan-Wright EM, Nash K, Lewin AS, Mandel RJ. 2005. Intrastriatal rAAV-mediated delivery of anti-huntingtin
shRNAs induces partial reversal of disease progression in R6/1 Huntington's disease transgenic mice. Mol Ther 12:618-633.

Segal RA, Greenberg ME. 1996. Intracellular signaling pathways activated by neurotrophic factors. Annu Rev Neurosci 19:463-489.

Sendtner M, Kreutzberg GW, Thoenen H. 1990. Ciliary neurotrophic factor prevents the degeneration of motor neurons after axotomy. Nature 345:440-441.

Sharp AH, Loev SJ, Schilling G, Li SH, Li XJ, Bao J, Wagster MV, Kotzuk JA, Steiner JP, Lo A, Hedreen J, Sisodia S, Snyder SH, Dawson TM, Ryugo DK, Ross CA. 1995. Widespread expression of Huntington's-disease gene (It15) protein product. Neuron 14:1065-1074.

Sugars KL, Rubinsztein DC. 2003. Transcriptional abnormalities in Huntington disease. Trends Genet 19:233-238.

Taymans JM, Vandenberghe LH, Haute CV, Thiry I, Deroose CM, Mortelmans L, Wilson JM, Debyser Z, Baekelandt V. 2007. Comparative analysis of adeno-associated viral vector serotypes $1,2,5,7$, and 8 in mouse brain. Hum Gene Ther 18:195-206.

Trejo A, Tarrats RM, Alonso ME, Boll MC, Ochoa A, Velasquez L. 2004. Assessment of the nutrition status of patients with Huntington's disease. Nutrition 20:192-196.

Vergara C, Ramirez B. 2004. CNTF, a pleiotropic cytokine: emphasis on its myotrophic role. Brain Res Brain Res Rev 47:161-173.

Walling HW, Baldassare JJ, Westfall TC. 1998. Molecular aspects of Huntington's disease. J Neurosci Res 54:301-308.

Young AB, Penney JB, Starosta-Rubinstein S, Markel DS, Berent S, Giordani B, Ehrenkaufer R, Jewett D, Hichwa R. 1986. PET scan investigations of Huntington's disease: cerebral metabolic correlates of neurological features and functional decline. Ann Neurol 20:296303.

Zala D, Bensadoun JC, Pereira de Almeida L, Leavitt BR, Gutekunst CA, Aebischer P, Hayden MR, Deglon N. 2004. Long-term lentiviralmediated expression of ciliary neurotrophic factor in the striatum of Huntington's disease transgenic mice. Exp Neurol 185:26-35.

Zolotukhin S, Potter M, Zolotukhin I, Sakai Y, Loiler S, Fraites TJ Jr, Chiodo VA, Phillipsberg T, Muzyczka N, Hauswirth WW, Flotte TR, Byrne BJ, Snyder RO. 2002. Production and purification of serotype 1,2 , and 5 recombinant adeno-associated viral vectors. Methods 28:158-167.

Zuccato C, Tartari M, Crotti A, Goffredo D, Valenza M, Conti L, Cataudella T, Leavitt BR, Hayden MR, Timmusk T, Rigamonti D, Cattaneo E. 2003. Huntingtin interacts with REST/NRSF to modulate the transcription of NRSE-controlled neuronal genes. Nat Genet 35:76-83. 